Eos, Vol. 75, No. 26, June 28, 1994
E O S
T R A N S C T I O N S,
A M E R I C A N
G E O P H Y S I C A L
U N I O N

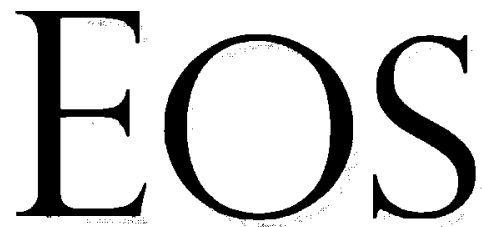

VOLUME 75 NUMBER 26

JUNE 28, 1994

PAGES 289-304

\title{
New Project to Support Scientific Collaboration Electronically
}

PAGES 289, 295, 298

\section{R. Clauer et al.}

A new multidisciplinary effort is linking research in the upper atmospheric and space, computer, and behavioral sciences to develop a prototype electronic environment for conducting team science worldwide. A realworld electronic collaboration testbed has been established to support scientific work centered around the experimental operations being conducted with instruments from the Sondrestrom Upper Atmospheric Research Facility in Kangerlussuaq, Greenland.

Such group computing environments will become an important component of the $\mathrm{Na}$ tional Information Infrastructure initiative, which is envisioned as the high-performance communications infrastructure to support national scientific research.

Because the upper atmosphere and space plasmas are influenced by diverse regions and processes, progress in understanding requires a synthesis of information from a variety of experimental data and interaction among scientists in many disciplines. The computing infrastructure to support such activity should facilitate collaborative efforts to acquire and synthesize information. The

C. R. Clauer, C. E. Rasmussen, R. J. Niciejewski, and T. L. Killeen, University of Michigan, Space Physics Research Laboratory, Ann Arbor, MI 48109; J. D. Kelly and Y. Zambre, SRI International, Geoscience and Engineering Center, 333 Ravenswood Ave., Menlo Park CA 94025; T. J. Rosenberg, University of Maryland, Institute for Physical Science and Technology, College Park, MD 20742; P. Stauning and E. Friis-Christensen, Danish Meteorological Institute, Solar Terrestrial Physics Division, Copenhagen, Denmark; S. B. Mende, Lockheed Palo Alto Research Laboratory, 3251 Hanover St., Palo Alto, CA 94304; T. E. Weymouth, A. Prakash, and S. E. McDaniel, University of Michigan, Dep. of Electrical Engineering and Computer Science, Ann Arbor, MI 48109; G. M. Olson and T. A. Finholt, University of Michigan, Cognitive Science and Machine Intelligence Laboratory, 701 Tappan, Ann Arbor, MI 48109 ; D. E. Atkins, University of Michigan, School of Information and Library Studies, 304 W. Engineering, Ann Arbor, MI 48109 technology to enable these interactions is now developing rapidly, and the United States is making a major commitment to develop and deploy such technology.

A step in this direction is the National Collaboratory, which will support interaction between people, access to remote information sources and digital libraries, and access to remote and unique facilities. The National Collaboratories Report, prepared by the National Research Council, describes the National Collaboratory as a "...center without walls in which the nation's researchers can perform research without regard to geographical location-interacting with colleagues, accessing instrumentation, sharing data and computational resources, and accessing information from digital libraries."

The report concludes, "...collaboratory testbed programs have the potential to address important scientific needs, while simultaneously representing a key step toward developing national and global infrastructure."

The Upper Atmospheric Research Collaboratory (UARC) prototype was designed to incorporate these interactive aspects and has been cooperatively funded by the Computer Information Science and Engineering Directorate (CISE) and the Atmospheric Sciences Directorate of the National Science Foundation since September 1992. To develop this approach as rapidly as possible, the UARC has been formed around the ongoing research activities of a group of space scientists who use the Sondrestrom Upper Atmospheric Research Facility in

Kangerlussuaq, Greenland.

The UARC employs a user-oriented, rapid prototyping approach at the University of Michigan, SRI International, and the other testbed sites-the Danish Meteorological Institute, the University of Maryland, and the Lockheed Palo Alto Research Laboratory.

The project supports a multidisciplinary group of investigators who conduct experi- mental research toward creating and evaluating distributed environments to support team science. A goal is to build a networked environment to support the coordinated collaborative research and interactive observational campaigns that use multiple instruments and are conducted by a distributed group of investigators located at home institutions. An early public demonstration of the UARC was given at the AGU's Spring 1993 AGU Meeting special session "Applications of Advanced Data Handling and Visualization Tools to Complex Problems in Space and Atmospheric Sciences."

\section{The Sondrestrom UARC Testbed}

The instruments participating in the UARC testbed include the incoherent scatter radar, imaging riometer, magnetometers, Perot interferometer and optical spectrometers and photometers, and an all-sky imaging television camera.

The testbed will evolve from a "wire service" to a fully shared electronic collaboration environment; we have completed the wire service phase, using existing technology to provide the underlying testbed foundation. In this phase the instruments can generate a stream of data that is collected, stored, forwarded, and displayed at all user sites. The wire service phase has now evolved to a "point and talk" phase, which allows researchers located at several distributed sites to interact using a set of simple communications windows that broadcast discussion to all interactive users. New developments in this phase will include shared windows, shared annotation to data and graphics, electronic blackboards (drawing windows), and voice communications.

Collected data will have to be reviewed and discussed at various times because of the group's time zone distribution. Thus tools that support synchronous real-time interactions are being designed to also support asynchronous collaboration. Such tools could, for example, permit a researcher to play back data collected from various instruments during a previous data collection interval, annotate the data, discuss the results using voice, and encapsulate this into a file that could be sent to a colleague who could play back the discussion on his own workstation. The colleague could edit the file by including his own comments and annotation, and send the file back. Because the 

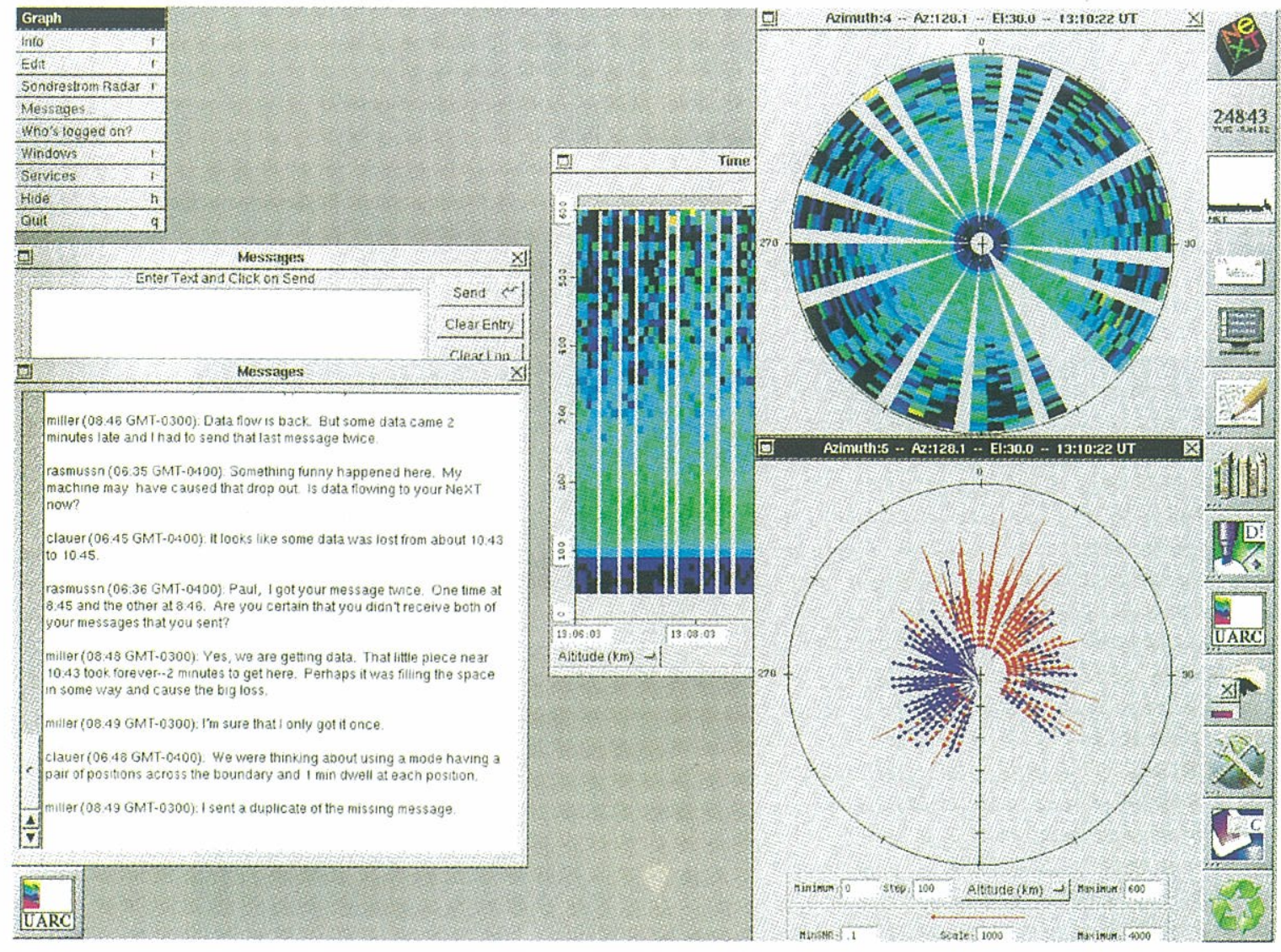

Fig. 1. Upper Atmospheric Research Center screen display obtained during the April 1993 radar campaign showing the dialogue box (left) and displays of radar data (top right), density versus azimuth (bottom right), line-of-sight velocity with color coded vectors red (away) and blue (toward), and a time plot of density versus altitude in the background.

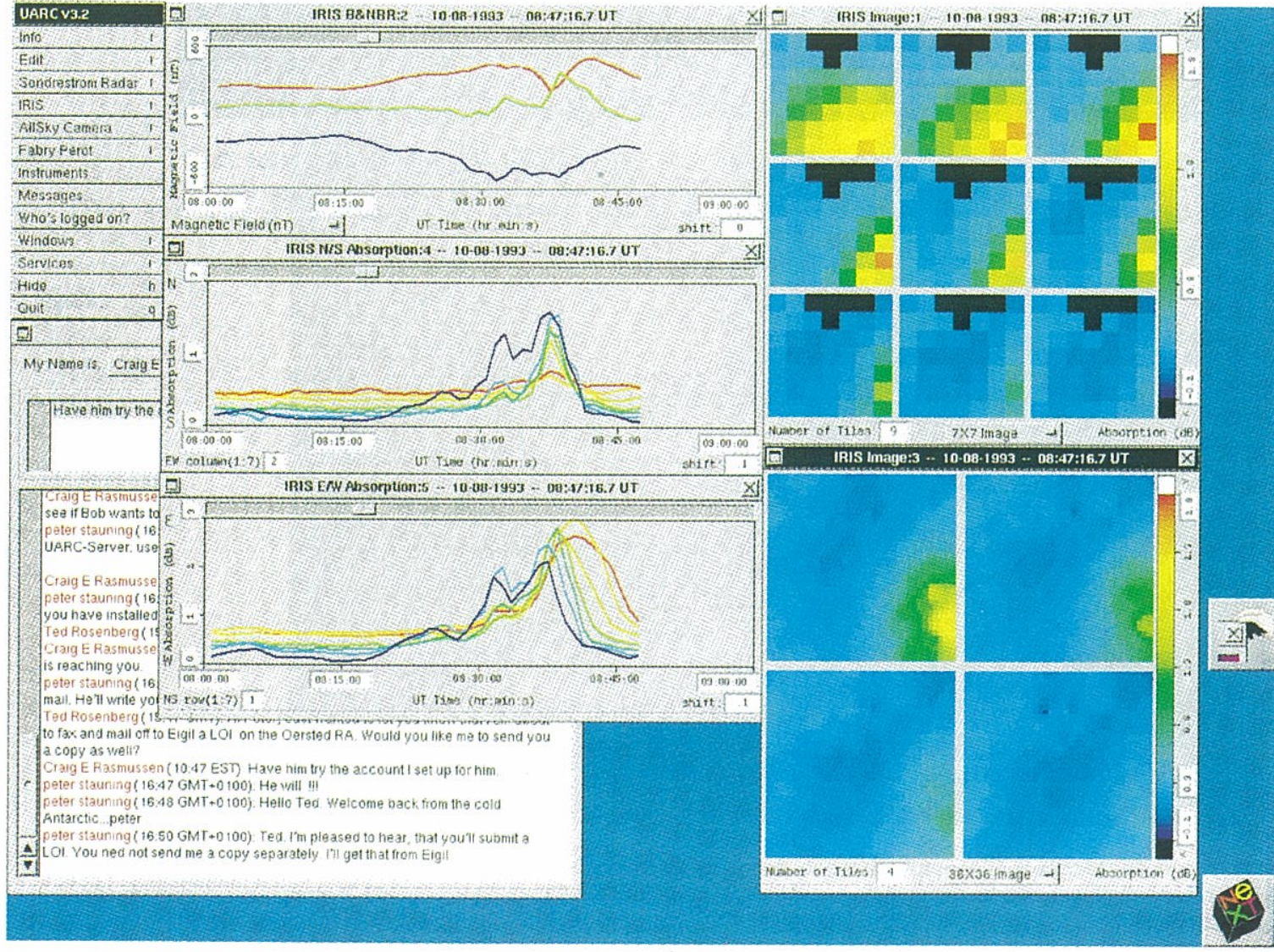

Fig. 2. UARC screen display showing data from the magnetometer (top left) and the imaging riometer (IRIS). The top right shows absorption intensity for each of the 7 $x 7$ elements of the IRIS for 9 consecutive min. The most recent image is in the bottom right corner. At bottom are four $36 \times 36$ pixel smoothed images of the last $4 \mathrm{~min}$ of IRIS data. The middle and bottom panels at left show absorption as a function of time for the beams in the second column of the IRIS and the first row of the IRIS, respectively. 
UARC prototype project is composed of few individuals and sites, we have chosen to develop the project within a homogenous computing environment to limit problems of interoperability issues among computers and operating systems. We are using NeXT workstations and the NeXTStep Interface Builder and operating system because it integrates the operating system, supporting software, and development environment under a unifying object-oriented software library.

NeXTStep also allows software objects running on one workstation to be easily accessed from other workstations on the Internet. This system is an example of the type of computing environment that will become common in the future. The use of the interface building tools, distributed object support, and object-oriented computing environment allows us to pursue a rapid prototyping approach to system design, deployment, and evaluation. As an example of the rapid progress, we have implemented lour major versions of the system in 1 year.

Figures 1 and 2 show screen displays from the current software captured from past operations. In Figure 1, the various windows on the display show the data acquired by the radar: line-of-sight velocity (bottom right) and electron density (top right) from an azimuth scan. In these displays, geodetic north is at the top of the plot, south at the bottom, and data values are displayed as a function of range and azimuth. For the velocity plot, away and toward velocities are coded by red and blue vectors, respectively.

Also shown are the communications windows: one for entering messages (top left) and one that displays messages sent by all users (bottom left). While threads of different conversations develop in the message window, this has not been a problem; users can choose whether to participate in conversations. Another data display window showing ionospheric plasma density as a function of time and altitude is partially visible underneath the two azimuth scan data display windows. The control menu window for the program is shown in the upper left corner and icons for other NeXT tools and applications are shown at right.

Figure 2 shows a display of the IRIS imaging riometer data and Sondrestrom magnetometer data. The upper right window shows a sequence of $7 \times 7$ images that correspond to the $7 \times 7$ imaging riometer array. Images are acquired every minute; the most recent image is in the bottom right corner. The bottom right window shows the last four images smoothed to give a $36 \times 36$ pixel display. The traces in the windows to the left of the images are from the magnetometer (top), the second column of imaging riometer beams (middle), and the first row of imaging riometer beams (bottom). These data are displayed as a function of time. The message window appears in the background. Additional displays for these and other instruments are also available.
An important aspect of this multidisciplinary effort is a behavioral science component. Behavioral scientists are directing the object-oriented design

methodologies and monitoring the software usage to assist in the iterative redesign of the system.

The behavioral scientists are also documenting the eflect of this new technology on the scientific practice of the testbed users. Concurrent with the startup phase, the behavioral scientists surveyed the current work practices of the space scientists at various sites and of those who have undertaken research at the Greenland facility. These measurements will help assess the effects of the new technology and help quantify the project's benefits to the space science community.

Two Greenland observational campaigns were supported during the initial development of the UARC in April and June 1993. Between the campaigns, the collaboratory was altered on the basis of feedback from users and analyses by the behavioral scientists. The effectiveness of the changes can be studied through the messages exchanged by users in April and June: Exchanges were coded into several categories representing major topics of conversation, including science-such as discussion of upper atmospheric phenomena; technology-such as discussion about features and bugs in the collaboratory system; coordination- discussion about choosing a common data display across distributed sites; and socializingsuch as jokes and friendly banter.

It was predicted that as the collaboratory evolved toward a scientifically useful system, science content communication would increase over technology content following the collaboratory modifications. Comparison of the plots in Figure 3 confirms that this happened; the top of the figure shows that $27 \%$ of the words exchanged in April had technology content, while $28 \%$ of the words had science content. The bottom of the figure shows that the percentage of words with technology content dropped slightly to $22 \%$ in June, while the percentage of words with science content increased to $49 \%$. This result not only validates the design philosophy, but shows that the system and user interface developers were able to rapidly and efficently respond to the needs of the space science users.

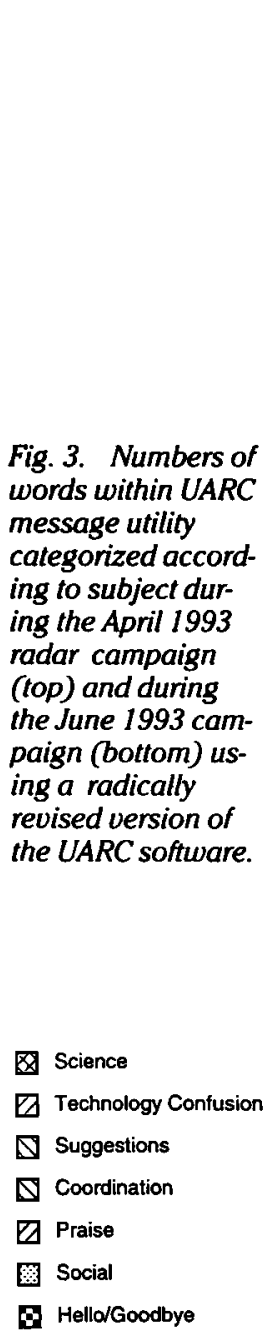

(top) and during

the June $1993 \mathrm{cam}$ paign (bottom) using a radically revised version of the UARC software.
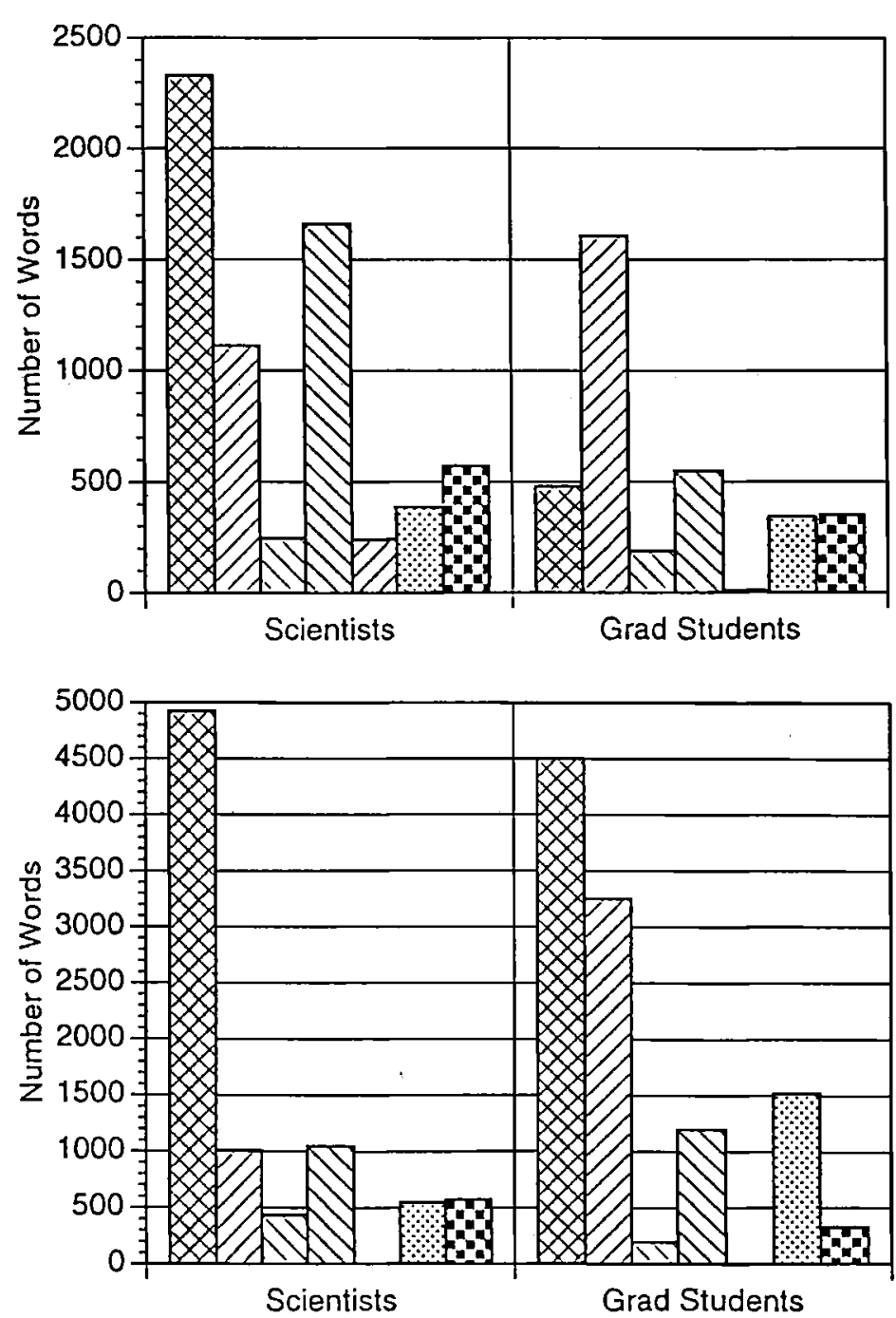


\section{Future Development}

The UARC is unique in several ways. We are developing design specifications that will be appropriate for the computing environments envisioned for the future, in say 5 or 10 years. A design goal is to yield a soltware product that users can tailor to suit their purposes-even a user not sophisticated in programming should be able to tailor the system to the source of data input and the types of data displays desired.

The project is coupled with a real-world user community where users provide immediate feedback in a rapid prototyping design environment. This enables software to be developed that meets user needs much more effectively than the typical design and development scheme for software packages. While the software is shaped by the community and is customized in many ways, generic principles of design are being developed.

This collaborative technology should be widely applicable to the space science community as well as to other scientific communities. Since much of the collaboration technology is expected to also have generic value, development here may also benefit future technology in other areas, such as education, engineering, and business.

As we consider the possibilities for extension of the UARC, issues of interoperability become more important. Since NeXTStep is now available to install on Intel 486 processors, it is relatively easy and inexpensive to join the homogenous UARC development environment. Hewlett Packard and SUN have announced that they will support NeXTStep or similar environments on their high performance RISC workstations. Still, we realize that this is not optimal for general expansion.

A more general way to address the interoperability issue is to view the UARC soltware under the NeXTStep environment as a formal, evolving design specification. Such a specification could then be used to implement collaboration software on other platforms. The NeXTStep version of the UARC software provides an demonstrative example of the specification for the user-interface, and the functionality required, on other platforms. Toward this end, we have begun to provide access to the UARC system from the $X$ Windows environments. A UARC client with $X$ Window-based display software could initially continue to run using the NeXT UARC server and its dis- tributed-object technology for communication. Other strategies for extending and scaling the testbed are also being researched in addition to access to archival data for collaborative team investigation.

\section{Acknowledgments}

Support for this work has been provided by the National Science Foundation through cooperative agreement IRI-9216848 to the University of Michigan and research has been supported by grant ATM-9106958. The Sondrestrom Upper Atmospheric Research Center is operated by SRI International for NSF through cooperative agreement ATM8822560 and is also partly supported by the Danish Meteorological Institute.

\section{Additional Authors}

J. D. Kelly, T. J. Rosenberg, C. E. Rasmussen, P. Stauning, E. Friis-Christensen, R. J. Niciejewski, T. L. Killeen, S. B. Mende, Y. Zambre, T. E. Weymouth, A. Prakash, S. E. McDaniel, G. M. Olson, T. A. Finholt, and D. E. Atkins

\section{References}

National Collaboratories, National Academy Press, Washington, D.C., 1993.

\section{Loma Prieta Damage Largely Attributed to Enhanced Ground Shaking}

PAGES 299, 300, 301

\section{Thomas L. Holzer}

Earthquake hazards are commonly treated independently by Earth scientists, yet when a large earthquake occurs, property losses are seldom totaled separately for each earthquake hazard. Four years after the 1989 Loma Prieta earthquake rolled through northern California, a quantitative answer to the following question is not yet available: How much damage was caused by ground shaking, liquefaction, landslides, tectonic ground rupture, or tsunami?

Although the consequences of one earthquake do not necessarily follow for others, an answer to this question will help guide public policy and set research priorities. The cost effectiveness of earthquake hazard mitigation can be improved when the relative significance of earthquake hazards is known because it enables public agencies to concentrate mitigation efforts on the most portentous hazards.

U.S. Geological Survey, 345 Middlefield Road, MS 977, Menlo Park, CA 94025-3591
An answer also encourages costeffective, problem-focused research by providing a rational basis for allocating research dollars. This is particularly timely because congressional reauthorization of the National Earthquake Hazards Reduction Program is currently under debate. A congressionally mandated review of the program criticized its lack of coordinated programmatic strategic planning, which would direct its resources into efforts that are priority-ranked and problem-focused. The program review also emphasized a need for greater incentives to implement earthquake risk reduction measures. Identifying the relative importance of earthquake hazards helps set priorities for both problem-focused research and implementation.

\section{The 1989 Loma Prieta Earthquake}

The moment magnitude 6.9 Loma Prieta earthquake, which hit at 5:04 p.m. PDT on October 17, 1989, was the largest earthquake to shake the San Francisco and Monterey Bay areas since the great San Francisco earthquake of 1906 (Figure 1).

Ground shaking from the earthquake was felt over an area of more than $1,000,000 \mathrm{~km}^{2}$, and damaging ground motions were observed at epicentral distances of approximately $100 \mathrm{~km}$ along selected azimuths [Plafker and Galloway, 1989]. Damaging liquefaction and landsliding were triggered at similar epicentral distances. Large ground cracks-not related to shallow downslope movements-occurred in the epicentral region and damaged houses, roads, and underground utilities. In addition, a small, but nondamaging, tsunami was observed at Moss Landing on Monterey Bay.

The earthquake caused sixty-three fatalities and 3757 injuries [McNutt, 1990]. At least 12,000 people were displaced from their homes. Physical losses included damage to 23,408 private homes and the destruction of 1018. In addition, 3530 commercial buildings were damaged and 366 were destroyed. Three bridges suffered collapses of one or more spans, and major port and airport facilities experienced significant damage.

Electrical service was internupted to approximately 1.4 million customers, and normal gas service was interrupted to 150,000 customers, about $90 \%$ of whom turned off their gas supply after the earthquake.

\section{Cost of the Earthquake}

The California State Olfice of Emergency Services (OES) estimated that the losses associated with direct property damage and 